\title{
Comparative study between bone patellar tendon bone and quadrupled hamstring autografts in arthroscopic anterior cruciate ligament reconstruction with aperture fixation
}

\author{
Dilip S. Shaktawat, Anil Kumar Mishra, Manoj R. Kashid*, Amit Chaudhry, \\ Rajshekhar, Abin Stanely
}

Department of Orthopaedics, Military Hospital Kirkee, Pune, Maharashtra, India

Received: 03 January 2017

Accepted: 18 January 2017

*Correspondence:

Dr. Manoj R. Kashid,

E-mail: manojkashid@yahoo.com

Copyright: (c) the author(s), publisher and licensee Medip Academy. This is an open-access article distributed under the terms of the Creative Commons Attribution Non-Commercial License, which permits unrestricted non-commercial use, distribution, and reproduction in any medium, provided the original work is properly cited.

\begin{abstract}
Background: Bone patellar tendon bone (BPTB) and hamstring (HT) auto grafts have been used routinely in reconstruction of ACL over past two decades. Controversy still remains as to which graft is superior over other. Many studies have compared these graft options using different implants and different methods of fixation. Continuation of efforts in the same direction; purpose of the study is to compare these two graft options utilizing identical implants and similar method of fixation.

Methods: 40 patients of clinically and radiologically diagnosed ACL tear fulfilling the inclusion and exclusion criteria were randomized into two groups to undergo arthroscopic ACL reconstruction using quadrupled hamstring graft $(n=20)$ and bone patellar tendon bone auto graft $(n=20)$ utilizing bioscrew by aperture fixation method in both the groups. They were compared post operatively for symptomatic improvement, clinical and rolimeter laxity tests and Lysholm functional knee scoring at 02 year.

Results: At the end of 02 years laxity measurement by rolimeter showed slightly better results in BPTB group; however it was not statistically significant ( $\mathrm{p}$ value $=0.362$ ). Knee pain at the end of 02 year was slightly more in HT groups $(45 \%)$ as compared to BPTB group $(35 \%)$ but not significant (p value $=0.748$ ). Instability symptoms are comparable in both the groups (sense of giving away on exertion). Manual laxity testing by Lachman and Pivot shift tests were comparable in both the groups with p value of 0.695 and 0.999 respectively. Lysholm functional knee score also showed no statistical significance ( $\mathrm{p}$ value $=0.957$ ).

Conclusions: There is no significant difference between HT and BPTB auto grafts in terms of clinical and functional outcome at the end of 02 years.
\end{abstract}

Keywords: Hamstring autograft (HT), Bone patellar tendon bone graft (BPTB), ACL reconstruction

\section{INTRODUCTION}

One of the controversial topics in ACL reconstruction is the choice of a graft and its fixation. ${ }^{1}$ The mid third patellar tendon and multiple- stranded hamstring tendons (semitendinosus and gracilis) are the most frequently used auto grafts today. ${ }^{1-3}$ The bone-patellar tendon-bone auto graft (BPTB) is considered to be the gold standard because of the bone-to-bone healing that allows for an early and accelerated rehabilitation with documented good and excellent long-term results. ${ }^{4,5}$ During the past few years, hamstring tendon (HT) grafts have increased in popularity as an alternative to the bone-patellar tendon-bone graft. $^{6}$ There are numerous studies comparing these both grafts in ACL reconstruction; however in most of the studies both the grafts are fixed 
using different materials (for example endobutton for hamstring and interference screw for BPTB grafts). The purpose of the present study was to compare bonepatellar tendon-bone and 4-strand hamstring tendon auto grafts in arthroscopic single incision ACL reconstruction, with biodegradable interference screw by aperture fixation method for both grafts in a prospective, matchedgroup.

\section{METHODS}

It is a prospective study of the cohort with ACL insufficiency treated with arthroscopic assisted ACL reconstruction using autologus quadrupled hamstring tendon graft (HT) in one group and bone patellar tendon bone (BPTB) graft in other group; performed at tertiary care hospital over a period of 36 months from December 2013 to January 2017. Institutional approval was obtained from the institutional ethics committee prior to the initiation of the study.40 Young serving soldiers between the age group of 18 to 40 years who are involved in vigorous activities with Clinical and radiological evidence of anterior cruciate ligament deficiency were selected after the acute inflammatory phase of the injury has subsided and full range of motion and good quadriceps strength has been regained with no extensor lag (usually after 4-6 weeks of injury). Patients with bilateral ACL tear, any other associated ligament injuries of the Knee (posterior cruciate ligament, medial and lateral collateral ligament), meniscal injuries more than grade II and those with articular cartilage injuries were excluded from the study. Patients were divided into two groups, each consisting of 20 patients by computer generated random number table. In one group (HT) quadrupled hamstring tendon is used and in other group (BPTB) central $1 / 3$ of patellar tendon along with bone plugs from patella and tibial tuberosity is used for reconstruction of ACL. In both the groups grafts were fixed at both femoral and tibial end with aperture fixation technique using bioniterference screw (Smith and Nephew). All the procedures in both groups were carried out with single surgeon. A standard rehabilitation protocol was followed (after Reid, 1992) for all patients. The subjects were evaluated at multiple intervals of 06 months, 01 year and 02 year. Post-operatively all the patients were subjected to manual laxity testing (Lachman, pivot shift test) and objective laxity is measured by rolimeter. At these intervals all the patients were evaluated by the modified Lysholm knee scoring system (1985). All the patients were also analyzed for their symptoms pre and post operatively.

\section{Statistical analysis}

Statistical analysis was done using SPSS software (IBM Version-20). Statistical difference between continuous variables was assessed using Student t-test. Categorical variables were compared using Chi square test. Statistical significance was set at $\mathrm{P}$ value of 0.05 or less.

\section{RESULTS}

The mean age of patients (in years) in our study in hamstring tendon graft group was 31.15 \pm 2.41 and in bone patellar tendon bone (BPTB) graft group was 31.00 \pm 2.53 . The two groups were analyzed statistically and there was no statistical significance between both the groups $(\mathrm{P}=0.849)$. Similarly there was no statistically significant difference between weight of the patients in both the groups (p-value-0.975) and duration of symptoms till time of surgery ( $\mathrm{p}$-value $=0.079$ ). Thus both the groups were comparable in these parameters as shown in Table 1.

Table 1: Distribution of age, weight and duration of symptoms between two groups.

\begin{tabular}{|lllll|}
\hline Groups & No of patients & Mean age (years) & Mean weight $(\mathrm{Kg})$ & Duration of symptoms (months) \\
\hline HT & 20 & $31.15 \pm 2.41$ & $74.50 \pm 5.09$ & $12.45+10.34$ \\
\hline BPTB & 20 & $31.00 \pm 2.53$ & $74.45 \pm 4.77$ & $7.90+4.09$ \\
\hline P-value & 0.849 & 0.975 & 0.079 \\
\hline
\end{tabular}

Table 2: Pre and postoperative assessment of laxity testing by rolimeter in both groups.

\begin{tabular}{|c|c|c|c|}
\hline \multirow{2}{*}{ Status } & HT $(n=$ & BPTB $(n=20)$ & \multirow[b]{2}{*}{ P-value } \\
\hline & Mean (mm) & Mean $(\mathbf{m m})$ & \\
\hline Preoperative & $7.30 \pm 1.98$ & $7.40 \pm 2.26$ & 0.882 \\
\hline Postoperative ( 2 years) & $4.00 \pm 1.08$ & $3.70 \pm 0.98$ & 0.362 \\
\hline
\end{tabular}

Postoperatively 9 cases $(45 \%)$ in HT group and 7 cases $(35 \%)$ in BPTB group complained of knee pain, 1 case $(5 \%)$ in BPTB group complained of giving away during normal activities of life whereas, 7 cases $(35 \%)$ in both groups complained of a slight sense of giving away during exertion or playing. 1 case $(5 \%)$ HT group and 2 cases in BPTB group (10\%) had swelling in the knee joint during exertion as given in Figure 1.
The mean pre-operative rolimeter measurement in HT tendon group was $7.30 \pm 1.98 \mathrm{SD}$, and in BPTB group it was 7.40 \pm 2.26 . The mean postoperative rolimeter measurement at 02 year follow up was $4.00 \pm 1.08 \mathrm{SD}$ in HT group and 3.70 $\pm 0.98 \mathrm{SD}$ in BPTB group. The results of pre and postoperative measurement by rolimeter were statistically analyzed and there was no statistical significance in both the groups with $\mathrm{P}=0.882$ 
preoperatively and $\mathrm{P}=0.362$ post-operatively as given in Table 2.

Postoperatively 02 cases (10\%) in HT group and 05 cases (25\%) in BPTB group had no laxity (negative). 17 cases $(85 \%)$ in HT group and 14 cases $(70 \%)$ in BPTB group had grade -I laxity but with firm end point. 01 case (5\%) in both the groups had grade-II laxity. The results of Pre and post-operative Lachman test were statistically analyzed and there was no statistical significance in both the groups with $\mathrm{P}=0.999$ preoperatively and $\mathrm{P}=0.695$ postoperatively as shown in Table 3 .

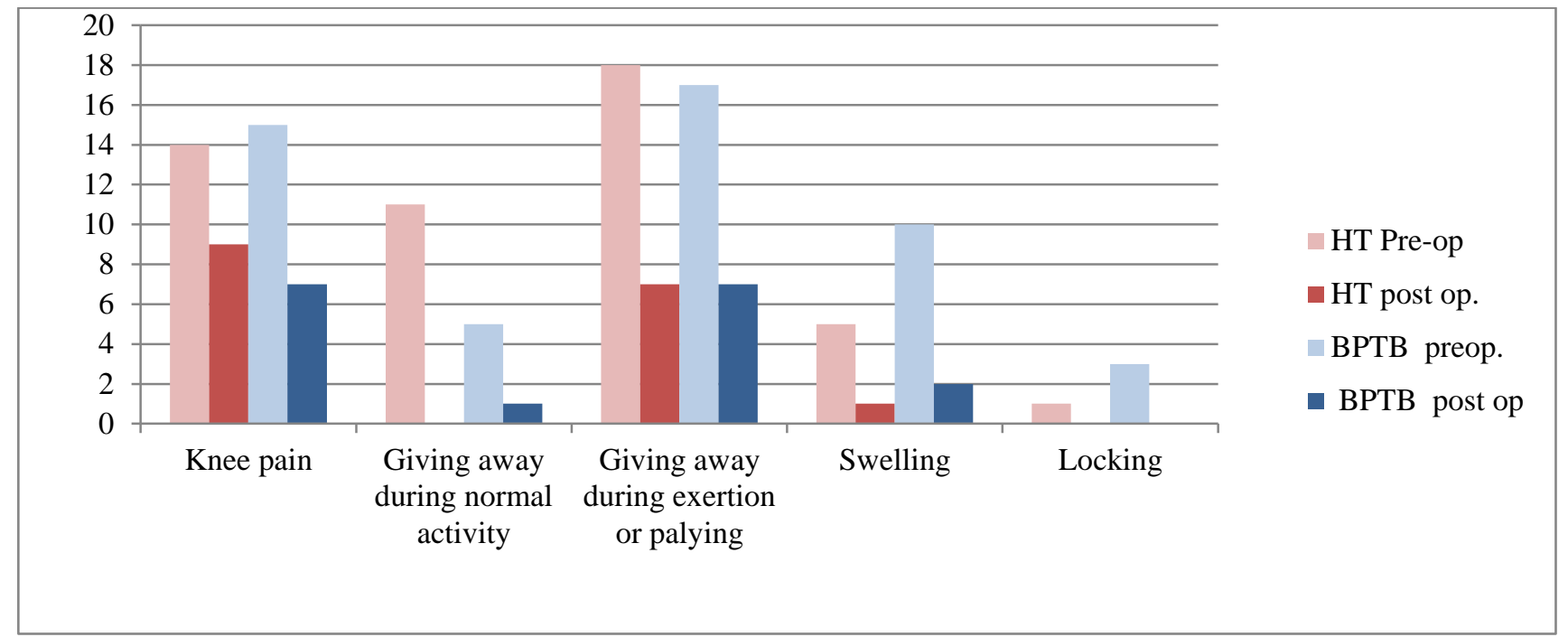

$\mathrm{X}$ axis denotes symptoms of the patient; $\mathrm{Y}$ axis denotes number of patients.

Figure 1: Preoperative and postoperative symptom profile of both groups.

Table 3: Pre and postoperative comparative assessment of Lachman test in both groups.

\begin{tabular}{|c|c|c|c|c|c|c|c|}
\hline & \multirow{2}{*}{ Groups } & \multicolumn{4}{|c|}{ Lachman test } & \multirow{2}{*}{ Total } & \multirow{2}{*}{ P-value } \\
\hline & & Nil & Grade I & Grade II & Grade III & & \\
\hline \multirow{2}{*}{ Preoperative } & HT & 0 & 2 & 15 & 3 & 20 & \multirow{2}{*}{0.999} \\
\hline & ВРTB & 0 & 2 & 14 & 4 & 20 & \\
\hline \multirow{2}{*}{ Postoperative (2 years) } & HT & 2 & 17 & 1 & 0 & 20 & \multirow{2}{*}{0.695} \\
\hline & BPTB & 5 & 14 & 1 & 0 & 20 & \\
\hline
\end{tabular}

Table 4: Pre and postoperative comparative assessment of pivot shift test in both groups.

\begin{tabular}{|c|c|c|c|c|c|c|c|}
\hline & \multirow{2}{*}{ Groups } & \multicolumn{4}{|c|}{ Pivot shift test } & \multirow{2}{*}{ Total } & \multirow{2}{*}{ P-value } \\
\hline & & Nil & Grade I & Grade II & Grade III & & \\
\hline \multirow{2}{*}{ Preoperative } & HT & 0 & 15 & 2 & 3 & 20 & \multirow{2}{*}{0.999} \\
\hline & ВPTB & 0 & 14 & 3 & 3 & 20 & \\
\hline \multirow{2}{*}{ Postoperative (2 years) } & HT & 19 & 1 & 0 & 0 & 20 & \multirow{2}{*}{0.999} \\
\hline & BPTB & 19 & 1 & 0 & 0 & 20 & \\
\hline
\end{tabular}

Table 5: Pre and postoperative comparative assessment of both groups with Lysholm knee score.

\begin{tabular}{|lll|l|}
\hline \multicolumn{1}{|c|}{ Status } & \multicolumn{1}{c|}{ HT $(\mathbf{n = 2 0})$} & \multicolumn{1}{c|}{ BPTB $(\mathbf{n = 2 0})$} & P-value \\
\hline Preoperative & Mean Lysholm score & Mean Lysholm score & 0.281 \\
\hline Postoperative (2 years) & $56.85 \pm 6.90$ & $54.70 \pm 5.44$ & 0.957 \\
\hline
\end{tabular}

Postoperatively at 02 year follow up; 01 case $(5 \%)$ in each of the two groups had a positive pivot shift test with a "Glide" (Grade-I), whereas remaining 19 cases (95\%) in both the groups had a negative pivot shift test. The results of pre and postoperative pivot shift test were statistically analyzed and there was no significance in both the groups. $\mathrm{P}=0.999$ pre-operatively and $\mathrm{P}=0.999$ postoperatively as given in Table 4 . 
Overall results of ACL reconstruction in both the groups were assessed by Lysholm knee score. In this series Lysholm score was recorded at 12 months and 2 year post-operatively. At 02 year follow up post-operatively 9 cases $(45 \%)$ in HT group and 10 cases $(50 \%)$ in BPTB group had excellent score (>91). Good score (77-90) was seen in 10 cases $(50 \%)$ of HT group and 9 cases $(45 \%)$ of BPTB group. The overall satisfactory result (excellent + good) in both the groups at 02 year follow up was $95 \%$.

Out of this, 19 patients $(95 \%)$ in HT group and 19 patients $(95 \%)$ in BPTB group were able to achieve preinjury activity level. They were upgraded and considered fit to resume all active military duties. The mean postoperative Lysholm score in HT group improved to $87.80 \pm 5.54$ and in BPTB group it improved to $87.90 \pm 6.11$. The mean pre and postoperative Lysholm scores at 02 year follow up were statistically analyzed using two independent sample t-test. There is no statistical significance in the mean post-operative Lysholm scores in both the groups ( $\mathrm{P}$ value-0.957) as given in Table 5.

\section{DISCUSSION}

The BPTB and four-strand hamstring grafts (HT) are the most common currently used grafts for ACL reconstruction. BPTB autografts have been used for years with excellent results at long term follow-up. The central third of the patellar tendon along with bone plugs from the patella and the tibial tubercle is considered the "gold standard" by many surgeons. ${ }^{9}$ BPTB grafts have the advantage of bone-to-bone healing, which has been shown to be faster and more reliable than tendon to bone healing. ${ }^{13,14}$ BPTB autograft does have several disadvantages that have been described in the literature. First, the bone-patellar tendon-bone graft is a fixed length grafts and, as such, is vulnerable to graft tunnel mismatch when tunnel length is not accordingly adjusted. Another well documented disadvantage of BPTB autografts is a higher incidence of anterior knee pain. BPTB grafts demonstrated a trend towards reduced extension strength. Patella fracture is another concern following ACL reconstruction using BPTB autograft.

Advantages of hamstrings autograft are low donor site morbidity, avoidance of extensor mechanism problems and better cosmoses. Hamstrings tendon grafts, however, are not without their disadvantages. Hamstring tendon grafts also may increase in laxity over time. Another disadvantage to using hamstrings tendon grafts is that soft-tissue to bone healing takes longer than bone-to-bone healing and is less reliable. ${ }^{15}$ Soft tissue grafts may also have a propensity to cause tunnel widening. ${ }^{16}$ However, there is little evidence that tunnel widening affects clinical or arthrometric outcomes following ACL reconstruction. ${ }^{17}$ Many studies evaluating the morbidity of hamstring tendon harvest have demonstrated reduced knee flexion strength compared with the contra lateral extremity. However, in ACL reconstructed knees, a flexion strength deficit occurs but has no effect on IKDC scores. ${ }^{18}$

The purpose of this study was to compare bone-patellar tendon-bone and 4-strand hamstring tendon autografts for arthroscopic ACL reconstruction with the same type of fixation for both grafts. Other authors have compared these grafts in clinical outcome studies but have used different fixation devices for the hamstring tendons and the patellar tendon grafts. $7,9,11$

Most of these investigations showed better static stability when a patellar tendon graft was used. This finding might be attributable to the fact that extra cortical fixation, often used with hamstring tendon grafts, might result in inferior mechanical and biological boundary conditions. It is unwise to compare two different graft materials using different methods and methods of fixation.

Few studies have used identical fixation devices for hamstring tendon and patellar tendon grafts. ${ }^{8,10,19}$ Beard et al showed no significant differences concerning IKDC and Lysholm scores and KT-1000 arthrometer measurement using a fixation technique with titanium interference screws for both grafts in a 1-year follow-up study of 45 patients. $^{8}$ Ejerhed et al found no significant difference in the Lysholm, Tegner, and IKDC scores and significantly better ability in knee walking in the hamstring tendon group 2 years after surgery using titanium interference screws for both grafts. ${ }^{10}$ Corry et al demonstrated no differences concerning stability, range of motion, and general symptoms 1 and 2 years after surgery, but they found less thigh atrophy in the hamstring tendon group after 1 year. ${ }^{19}$ This difference disappeared 2 years after surgery, but hamstring tendon patients showed significantly better ability in knee walking after 2 years.

Our study utilizes bio absorbable interference screw for fixation of both the grafts at the femoral end. Laxity measurement by rolimeter at 02 years showed slightly better results in BРTB group; however it was not statistically significant ( $\mathrm{p}$ value-0.362). Knee pain at the end of 02 year was slightly more in HT groups (45\%) as compared to BPTB group (35\%) but not significant( $\mathrm{p}$ value-0.748). Instability symptoms are comparable in both the groups (sense of giving away on exertion). Manual laxity testing by Lachman and pivot shift tests were comparable in both the groups at 02 year follow-up with $\mathrm{p}$ value of 0.695 and 0.999 respectively. Better laxity measurement in HT group might be contributed to aperture fixation method used in fixation of hamstring grafts. Lysholm functional knee score at the end of 02 years also showed no statistical significance ( $p$ value0.957). Thus both the graft are comparable at the end of 02 years as far as the patient satisfaction, laxity testing and functional outcomes are concerned. 
Prospective nature and randomization strengthens the study; however few short comings are small study group and relatively shorter follow-up period.

\section{CONCLUSION}

The short term results of arthroscopic ACL reconstruction using identical implants for hamstring and bone patellar tendon bone grafts; based on symptomatic improvement, manual and rolimeter laxity testing and Lysholm scoring system were almost similar, with each having its own advantages and disadvantages. There is no significant difference between both the groups in terms of functional outcome.

Funding: No funding sources

Conflict of interest: None declared

Ethical approval: The study was approved by the institutional ethics committee

\section{REFERENCES}

1. Bartlett R, Clatworthy M, Nguyen T. Graft selection in reconstruction of the anterior cruciate ligament. $\mathrm{J}$ Bone Joint Surg Br. 2001;83:625-34.

2. Frank CB, Jackson DW. The science of reconstruction of the anterior cruciate ligament. J Bone Joint Surg Am. 1997;79:1556-76.

3. O'Neill DB. Arthroscopically assisted reconstruction of the anterior cruciate ligament: a follow-up report. $\mathrm{J}$ Bone Joint Surg Am. 2001;83:1329-32.

4. Shelbourne KD, Gray T. Anterior cruciate ligament reconstruction with autogenous patellar tendon graft followed by accelerated rehabilitation: a two- to nine-year followup. Am J Sports Med. 1997;25:78695.

5. Yunes M, Richmond JC, Engels EA, Pinczewski LA. Patellar versus hamstring tendons in anterior cruciate ligament reconstruction: a meta-analysis. Arthroscopy. 2001;17:248-57.

6. Brown CH Jr, Steiner ME, Carson EW. The use of hamstring tendons for anterior cruciate ligament reconstruction: technique and results. Clin Sports Med. 1993;12:723-56.

7. Aune AK, Holm I, Risberg MA, Jensen HK, Steen H. Four-strand hamstring tendon autograft compared with patellar tendon-bone autograft for anterior cruciate ligament reconstruction: a randomized study with two-year follow-up. Am J Sports Med. 2001;29:722-8.

8. Beard DJ, Anderson JL, Davies S, Price AJ, Dodd CA. Hamstrings vs. patella tendon for anterior cruciate ligament reconstruction: a randomized controlled trial. Knee. 2001;8:45-50.

9. Beynnon BD, Johnson RJ, Fleming BC, Kannus P, Kaplan M, Samani J, et al. Anterior cruciate ligament replacement: comparison of bone-patellar tendon-bone grafts with two-strand hamstring grafts: a prospective, randomized study. J Bone Joint Surg Am. 2002;84:1503-13.

10. Ejerhed L, Kartus J, Sernert N, Kohler K, Karlsson J. Patellar tendon or semitendinosus tendon autografts for anterior cruciate ligament reconstruction? A prospective randomized study with a two-year follow- up. Am J Sports Med. 2003;31:19-25.

11. Feller JA, Webster KE. A randomized comparison of patellar tendon and hamstring tendon anterior cruciate ligament reconstruction. Am J Sports Med. 2003;31:564-73.

12. Brand J, Weiler A, Caborn DN, Brown $\mathrm{CH} \mathrm{Jr}$, Johnson DL. Graft fixation in cruciate ligament surgery: current concepts. Am J Sports Med. 2000;28:761-74.

13. Gulotta LV, Rodeo SA. Biology of autograft and allograft healing in anterior cruciate ligament reconstruction. Clin Sports Med. 2007;26:509-24.

14. Tomita F, Yasuda K, Mikami S, Sakai T, Yamazaki S, Tohyama H. Comparisons of intraosseous graft healing between the doubled flexor tendon graft and the bone-patellar tendonbone graft in anterior cruciate ligament reconstruction. Arthroscopy. 2001;17:461-76.

15. Park MJ, Lee MC, Seong SC. A comparative study of the healing of tendon autograft and tendon-bone autograft using patellar tendon in rabbits. Int Orthop. 2001;25:35-9.

16. L'Insalata JC, Klatt B, Fu FH, Harner CD. Tunnel expansion following anterior cruciate ligament reconstruction: a comparison of hamstring and patellar tendon autografts. Knee Surg Sports Traumatol Arthrosc. 1997;5:234-8.

17. Fauno $\mathrm{P}$, Kaalund $\mathrm{S}$. Tunnel widening after hamstring anterior cruciate ligament reconstruction is influenced by the type of graft fixation used: a prospective randomized study. Arthroscopy. 2005;21:1337-41.

18. Landes S, Nyland J, Elmlinger B, Tillett E, Caborn D. Knee flexor strength after ACL reconstruction: comparison between hamstring autograft, tibialis anterior allograft, and non-injured controls. Knee Surg Sports Traumatol Arthrosc. 2010;18:317-24.

19. Corry IS, Webb JM, Clingeleffer AJ, Pinczewski LA. Arthroscopic reconstruction of the anterior cruciate ligament: a comparison of patellar tendon autograft and four-strand hamstring tendon autograft. Am J Sports Med. 1999;27:444-54.

Cite this article as: Shaktawat DS, Mishra AK, Kashid MR, Chaudhry A, Rajshekhar, Stanely A. Comparative study between bone patellar tendon bone and quadrupled hamstring autografts in arthroscopic anterior cruciate ligament reconstruction with aperture fixation. Int J Res Orthop 2017;3:185-9. 